Relato de Experiência

\title{
O planejamento do "Recreio nas Férias" na cidade Paulista de Americana
}

\author{
Nayara Torre de Almeida \\ Débora Alice Machado da Silva \\ Grupo Práxis, Faculdade de Americana - FAM, Americana, SP, Brasil
}

\begin{abstract}
Resumo: $O$ presente artigo constitui um relato de experiência do processo de planejamento e implementação do projeto "Recreio nas Férias" em um dos núcleos do Programa Segundo Tempo, localizado no bairro Vila Jones na cidade Paulista de Americana. O Projeto "Recreio nas Férias" é uma iniciativa do Ministério do Esporte, implantada em 2009 com o objetivo de, no período de férias escolares, oferecer às crianças e adolescentes participantes do programa, opções de esporte e lazer (e.g., atividades lúdicas, esportivas, artísticas, culturais, sociais e turísticas) que "preencham o seu tempo livre de forma prazerosa e ao mesmo tempo construtiva" (BRASIL, 2010). Confrontando tais objetivos com os estudos mais atuais no campo do lazer é possível perceber que, no campo das políticas públicas, ainda permanece a visão histórica que tende a tratar o lazer como ocupação do tempo ocioso, principalmente quando se trata das propostas voltadas às classes populares. Isso fica evidente na preocupação explícita de "preencher o tempo livre", enfatizando seu caráter ocupacional. Nesse sentido, tecemos algumas aproximações com estudos de Silva $(\underline{2003}, \underline{2008})$ e Marcellino $(\underline{1995}, \underline{2001}, 2008)$ compreendendo o lazer como uma das possibilidades de vivência do lúdico e construção da cidadania, ou seja, buscando responder a seguinte questão: pode o lazer assumir outro papel, senão este "ocupacional" historicamente observado nas políticas de esporte e lazer voltadas às classes populares?
\end{abstract}

Palavras chave: atividades de lazer; planejamento; políticas públicas.

\section{Planning for the program "Leisure During the School Break" ("Recreio nas Férias") in the Brazilian city of Americana, State of São Paulo}

\begin{abstract}
This study reports the planning and the implementation of the program "Recreio nas Férias" in one of the centers of the program "Second Half" ("Programa Segundo Tempo"), located in Vila Jones in the Brazilian city of Americana, State of São Paulo. The program "Leisure During the School Break" ("Recreio nas Férias") is a project of the Ministry of Sports, lounged in 2009. The aim was, during the school break, to provide children and adolescents with sports and leisure activities (games, sports, artistic, cultural, social and tourism activities) "to fill the free time during school break with pleasant constructive ways" (BRASIL, 2010). Paralleling these goals with the current thinking in the academic field of leisure, we observe that public policies still reinforces the notion that leisure is an occupation for "passing the time", mainly when designed for the working classes. This is evident with the explicit concern of "to fill the free time", emphasizing its occupational character. Therefore, we discuss this situation under Silva $(2003,2008)$ and Marcellino (1995, 2001, 2008) approach in which leisure is one of many possibilities of living playfully and constructing citizenship. We attempt to answer the question: can leisure fulfill another role than this "passing the time" notion typically found in sport and leisure government policies for the working classes?
\end{abstract}

Keywords: leisure activities; planning; public policies.

\section{Introdução}

As políticas públicas de esporte e lazer têm ganhado certa evidência nos últimos anos. Desde 2004, com a realização da I Conferência Nacional de Esporte, seguida em 2006 e 2010 por edições subsequentes, tem-se evidenciado a importância da formulação de agendas para o esporte e o lazer no Brasil, com vista à construção do Sistema Nacional de Esporte e Lazer.

Um dos eixos que tem sido, sistematicamente, discutido nas conferências é o de "gestão e controle social", cujos resultados apontam para "o princípio da gestão democrática, objetivando o exercício pleno da cidadania" (BRASIL, 2006). Dentro desse eixo identificamos 0 estabelecimento de convênios, consórcios e cooperações "a fim de viabilizar ações que estimulem e promovam o esporte e o lazer" (idem, p. 27). Considerando que o Programa Segundo Tempo é uma ação finalística da Secretaria Nacional de Esporte Educacional do Ministério do Esporte sua destinação orçamentária deve ser executada por meio de parcerias e convênios. 
O "Recreio nas Férias" é um projeto integrante do programa Segundo Tempo, cuja finalidade é oferecer atividades específicas para crianças e adolescentes no período de férias escolares. Nas diretrizes do programa são incentivadas opções de lazer diferenciadas daquelas desenvolvidas de maneira sistemática dos núcleos (futebol, vôlei, basquete, handebol, xadrez). Sua finalidade principal é "preencher o tempo livre de forma prazerosa e ao mesmo tempo construtiva, por meio do desenvolvimento de atividades lúdicas, esportivas, artísticas, culturais, sociais e turísticas" (BRASIL, 2010). As atividades são planejadas a partir de temas geradores, cabendo a cada núcleo do programa considerar as características locais.

Sendo um projeto integrante de um programa mais amplo, o "Recreio nas Férias" possui uma verba específica para sua execução, implicando em convênios complementares. Além disso, visa alcançar objetivos específicos e diferencia-se das ações sistemáticas do programa por possuir um conjunto de atividades interrelacionadas e coordenadas que estão voltadas a um objetivo específico, a partir de delimitações claras em termos de tempo e orçamento.

No material didático do "Recreio nas Férias" podemos destacar seu objetivo específico: "trazer, de modo explícito e organizado, as dimensões do lazer e do lúdico para dentro do Programa Segundo Tempo, em suas atividades no período de férias escolares" (FILGUEIRA, 2009). No entanto, ao recorrer à literatura específica (MARCELLINO, 1996; MARCELLINO, 2001; ZINGONI, 2003; PINTO, 2008) pudemos verificar a necessidade de que as políticas setoriais de esporte e lazer superem perspectivas de caráter assistencialista, tecnicista e ocupacional, ampliando o entendimento destes termos no âmbito da gestão das políticas públicas e fomentando a educação para o esporte e para o lazer, além de utilizá-los como ferramentas de educação, desenvolvimento pessoal e social. Em suma, é fundamental que o esporte e o lazer possam ser entendidos "como parte da educação em geral e espaço de aprendizagem social" (BONALUME, 2001).

No entanto, dos programas e projetos de esporte e lazer no Brasil, em diferentes momentos históricos, Pinto (2008) aponta como marca registrada três elementos: (1) a questão da descontinuidade, relacionada às mudanças de governo e ao fato dos projetos sociais dessas áreas servirem como forma de propaganda eleitoral; (2) o fato de o esporte ser um setorial secundário na gestão das políticas públicas, o que pode ser analisado pelo montante de verbas alocadas nessas pastas, e pela sistemática indicação de gestores visando os "favores políticos" e não a competência técnica aliada à competência política para desenvolvimento da política setorial; e, finalmente (3) a predominância de investimentos em programas, projetos e ações isolados e de caráter ocupacional, denominada por vários autores (MARCELLINO, 1996 BRAMANTE, 1997) de "política de eventos".

No âmbito deste artigo, buscamos descrever a experiência do processo de implementação e planejamento do "Recreio nas Férias" identificando e analisando os fatores que contribuem para a superação das visões reducionistas de esporte e lazer, tomando por base alguns referenciais teóricos, específicos, relacionados à temática.

\section{Metodologia}

$\mathrm{Na}$ tentativa de analisar como esses aspectos são evidenciados na experiência como coordenadora de núcleo do programa Segundo Tempo, organizamos esse relato de experiência, que traz de maneira objetiva as diferentes etapas da implementação e planejamento do projeto "Recreio nas Férias", no núcleo da Vila Jones, no município de Americana.

Assim, optamos pela combinação de técnicas de pesquisa bibliográfica e documental (documentos do programa Segundo Tempo e do projeto "Recreio nas Férias") tecendo algumas reflexões e aproximações com elementos teóricos apresentados por Silva (2003, 2008) a respeito do planejamento e desenvolvimento de Colônias de Férias Temáticas ${ }^{1}$; e no que tange a atuação profissional desenvolvida na perspectiva da "Pedagogia da Animação" Marcellino (2005).

\footnotetext{
1 Termo adotado por Silva (2003, 2008) para designar os programas ou programações de colônias de férias que se desenvolvam com base na metodologia dialógica de Paulo Freire, pela delimitação de temas geradores, "lidos" na/a partir da realidade do grupo com o qual as atividades são coconstruídas, co-desenvolvidas e co-avaliadas na busca de novos sentidos e significados no lazer e no cotidiano. Para saber mais: SILVA, Débora A.M. Colônia de Férias Temática: fundamentando a ação a partir das contribuições de Paulo Freire. Biblioteca Digital da Universidade Metodista de Piracicaba, 2008; e, SILVA, Débora A. M. Colônia de Férias Temática: construindo uma metodologia de ação. Monografia. Biblioteca da FEF/Unicamp, 2003
} 
Para Carvalho (2005, p.100), "a pesquisa bibliográfica é a atividade de localização e consulta de fontes diversas de informação escrita para coletar dados gerais ou específicos a respeito de determinado tema".

Severino (2002) também descreve a técnica da pesquisa bibliográfica, organizando-a em vários momentos: o levantamento bibliográfico, seguido da definição das unidades de leitura conforme o objeto e objetivo estudado; as análises textual, temática, interpretativa, problematizando as questões apontadas nas unidades de leitura; e, finalmente, a sistematização desse processo com a elaboração de uma síntese pessoal.

Esse processo foi complementado com os documentos e registros pessoais do processo de planejamento e implementação do "Recreio nas Férias" do núcleo da Vila Jones, realizado em janeiro e julho de 2010, contando com a participação de 200 crianças e mobilizando 7 pessoas da equipe, além de representantes da comunidade.

\section{O "Recreio nas Férias" no bairro Vila Jones em Americana}

O município de Americana tem uma população de 210.701 mil habitantes e integra a Região Metropolitana de Campinas (RMC). A história do município está atrelada ao desenvolvimento da indústria têxtil no Brasil, tendo recebido imigrantes portugueses, norte-americanos $\mathrm{e}$ italianos. A cidade se destaca pela qualidade de vida, ocupando a 19a colocação no IDH do Estado de São Paulo e 59a no Brasil. Além disso, é reconhecida como potência esportiva no interior de São Paulo, guardando uma grande tradição na formação de atletas em várias modalidades. Nesse sentido, nos investimentos do setorial do esporte predominam as ações voltadas ao esporte de alto rendimento e, ao analisar o Plano Diretor do Município (AMERICANA, 2008), é possível verificar a inexistência de um plano de ação para o setor, o que parece reforçar a tendência verificada na literatura.

Analisando a realidade do município parece ficar evidente que a implementação do Segundo Tempo acabou assumindo a finalidade de "selecionar talentos esportivos" dentro das modalidades oferecidas, para posterior encaminhamento às equipes esportivas já existentes. No processo de formação de coordenadores e monitores do programa essa meta foi sistematicamente reafirmada.

As atividades sistemáticas (atletismo, natação, basquete, futsal, xadrez) do programa Segundo Tempo, segundo suas diretrizes, deveriam ser desenvolvidas a partir do entendimento de que "o esporte ultrapassa a ideia de estar voltado apenas para o ensino das técnicas, táticas e regras dos esportes, embora inclua esses aspectos." (OLIVEIRA \& FORNE, 2009). No entanto, na prática, as ações visavam atingir resultados prédeterminados em relação ao desenvolvimento motor e à aquisição de habilidades físicas específicas nas crianças, desconsiderando as dimensões culturais, políticas e sociais que envolvem a participação das mesmas.

Nessa perspectiva, parece predominar um entendimento do esporte, não como prática recreativa e de lazer, mas como atividade sistemática com vistas a um resultado específico. Se, por um lado essa visão permite planificar uma ação de desenvolvimento esportivo, por outro acabava se constituindo para algumas crianças como obrigação, o que, na realidade do núcleo, acabou acarretando a redução do número de participantes.

Marcellino (2001, 2008) afirma que o desenvolvimento de uma política de esporte e lazer consistente precisa considerar as três dimensões do esporte preconizadas na Constituição Brasileira (participação, educacional e alto rendimento). Ainda, agregar: (1) infraestrutura; (2) organização de políticas de formação de pessoas para atuar com esporte e lazer no nível comunitário; (3) desenvolvimento de políticas de animação que promovam uso e manutenção dos espaços e equipamentos e, na medida do possível, (4) a promoção de uma política de reordenamento do tempo.

Ao ampliar o entendimento da política de esporte e lazer para além da realização de eventos e promoção de atletas, é possível pensar a ação setorial em ampla relação com outros setoriais, como transporte, educação, cultura, assistência social e saúde. Nessa perspectiva, os programas e projetos de esporte e, especialmente os de lazer, podem assumir o papel de articuladores da intersetorialidade, promovendo uma "rede temática" (RODRIGUES, 2008) focada na garantia do esporte e do lazer como direitos sociais. 
O entendimento amplo de lazer - em termos de conteúdos culturais e da ação de difusão e participação nesses conteúdos - requer a necessidade de interdisciplinaridade, ou pelo menos a pluridisciplinaridade caminhando em busca da interdisciplinaridade, nas equipes que desenvolvem ações no setor, em razão de suas interfaces com o esporte, o turismo e as manifestações artísticas (MARCELLINO, 2008, p.26).

O entendimento do lazer como uma especificidade que pode ser desenvolvida em diferentes políticas setoriais, assumindo uma característica transversal, ainda é pouco compreendido e aceito no âmbito da gestão das políticas públicas. Essas tendem a desconsiderar o lazer, ou considerá-lo apenas em sua dimensão de entretenimento, esquecendo-se das possibilidades de desenvolvimento pessoal e social. Ao mesmo tempo, é inegável sua manifestação em várias políticas: programas e atividades culturais, escolas abertas aos finais de semana para o desenvolvimento de atividades esportivas e de lazer, oferecimento de atividades "sócio educativas" no âmbito da assistência social, programas especiais de transporte para atividades culturais (horários especiais, tarifas reduzidas). Desse ponto de vista, é possível destacar a importância da articulação de propostas de esporte e lazer como forma de ampliar o alcance e a efetividade das políticas, programas e projetos desenvolvidos nos município, de forma que crianças, jovens, adultos e idosos possam usufruir de tais políticas.

É nesse sentido que o projeto "Recreio nas Férias" trouxe uma grande contribuição para ação permanente do Segundo Tempo, apesar de restringir sua ação às crianças. Seu objetivo era "trazer de modo explícito e organizado, as dimensões do lazer e do lúdico para dentro do programa "Segundo Tempo", em suas atividades no período de férias escolares" (FILGUEIRA, 2009) e o processo de implementação em Americana aconteceu em janeiro e julho de 2010.

O núcleo do Segundo Tempo da Vila Jones contava com um público sistemático de aproximadamente 60 crianças e adolescentes em idade escolar. Na primeira versão do "Recreio nas Férias" participaram cerca de 160 crianças e adolescentes, na segunda alcançamos aproximadamente 100 participantes.

O "Recreio nas Férias" era realizado nos meses de férias escolares tendo duração de uma semana. $O$ projeto se caracterizava pela oferta de atividades recreativas e de lazer nos núcleos do Programa Segundo Tempo, sempre das 8 às 16 horas. As atividades eram organizadas a partir de um tema gerador que assumia o papel de eixo de convergência do planejamento. Os participantes se inscreviam espontaneamente, não havendo a necessidade de serem participantes das atividades sistemáticas do núcleo.

\section{$O$ processo de planejamento do "Recreio nas Férias"}

O planejar é uma atividade humana que permite percebermos a realidade, avaliarmos estratégias e construirmos referenciais futuros que sejam horizontes para nossas ações. Em geral, a ideia de planejamento está associada à necessidade de superar um problema, uma situação-limite, ou ainda alcançar uma nova meta ou objetivo. Existem vários tipos de planejamento: participativo, estratégico, urbano, familiar e, em todos esses casos, aparece de forma mais ou menos explícita a questão da organização deliberada de determinadas ações visando alcançar um objetivo, reconhecendo os fatores limitantes e antecipando alguns resultados na tentativa de alcançar esse objetivo pré-definido da melhor maneira possível.

\section{Zingoni (2007) considera que}

o futuro dos projetos sociais está fortemente vinculado ao seu planejamento e sua gestão. Gerir um projeto contido em um programa, que articula vários atores, [...], certamente não é uma tarefa fácil. É necessário planejá-lo, cuidadosamente, monitorá-lo com base em indicadores previamente estabelecidos e avaliar seus resultados. Essas etapas são necessárias e são bem sucedidas quando elaboradas no momento do planejamento.

Silva (2003, 2008), ao construir uma metodologia de ação para atuar com Colônias de Férias Temáticas, propõe a inversão de prioridades no processo do planejamento, considerando o ordenamento das seguintes etapas:

(1) reconhecimento das crianças como produtoras de cultura e identificação de suas formas de agir e dialogar com os bens culturais trazidos pelos adultos;

(2) alinhamento em relação à compreensão do que é uma colônia de férias, compartilhando os vários significados que cada profissional envolvido na equipe traz sua atuação profissional;

(3) reconhecimento da colônia de férias como possibilidade para a vivência do lúdico como 
elemento da cultura e, portanto, portador de significados que são compartilhados na experiência de lazer;

(4) o reconhecimento da diversidade existente nos programas de lazer, garantindo espaços para as múltiplas manifestações e reconhecendo que os conflitos não são indesejáveis, mas elementos necessários para construção do diálogo entre todos os envolvidos na programação;

(5) definição da estratégia para desenvolvimento da ação educativa na colônia de férias, a partir da perspectiva da "pedagogia da animação";

(6) finalmente, a definição do "que fazer" ou das atividades propriamente ditas, considerando os diferentes conteúdos culturais do lazer em seus três gêneros (praticar, conhecer e assistir) e, principalmente, a possibilidade do ócio.

Afirma ainda, que a escolha dos temas geradores deve partir da realidade de cada grupo e comunidade, sendo fundamental a vinculação de projetos desta natureza a políticas setoriais (esporte, cultura, educação) mais amplas que possam garantir a continuidade das ações e a participação da comunidade, superando as propostas tipo "pacote de atividades" e os "eventos", que se "vão com os ventos."

\section{Para autora, a programação}

necessita estar vinculada aos princípios e a política mais ampla, da instituição que lhe propõe, pois é, por meio de seus projetos, que as instituições - públicas ou privadas mostram a que fins estão engajadas (SILVA, 2008, p.52).

Em termos objetivos, a primeira temporada do projeto "Recreio nas Férias" esteve focada no tema "Meio Ambiente". Já na segunda temporada o tema escolhido foi "Valores Olímpicos". A definição dos temas geradores, diferente do que é apontado pela literatura, é realizada pela Secretaria Nacional de Esporte Educacional/ME, para o âmbito nacional, cabendo a cada núcleo a realização do diagnóstico local para aproximação com a temática. Decorre daí que, determinadas temáticas podem estar muito distantes da realidade dos núcleos. Isso exige sensibilidade da equipe profissional no sentido de não transformar a experiência de lazer num processo de "escolarização da vivência do lazer" sob a necessidade de tratar a qualquer preço a temática proposta.
Ainda analisando a metodologia proposta por Silva (2008), é possível verificar uma ação pautada pela práxis dialógica, coletiva e participativa em todas as etapas do planejamento.

Ao valorizar a dimensão educativa da experiência esportiva e de lazer, a proposta passa a se engajar com a garantia da vivência do lúdico como elemento necessário às crianças no cotidiano. Busca assim, superar a relação opressora entre adultos e crianças por meio da valorização da produção cultural das crianças, e da relação desta com os padrões culturais próprios do universo adulto. Ainda, permite situar a discussão do lazer no campo do ordinário, do cotidiano e, não exclusivamente, como experiência extraordinária reservada ao período das férias.

Ao analisarmos os estudos de Silva (2003, 2008), é possível verificar que a definição dos temas geradores não decorre da inspiração dos cargos burocráticos responsáveis pela gestão de programas e projetos desta natureza, mas que são delimitados na experiência compartilhada entre adultos e crianças a partir de um diagnóstico bem elaborado que permita realizar uma "leitura do mundo" (FREIRE, 2007) - sob a ótica das crianças e com a mediação do adulto em relação aos bens culturais.

Quando Freire (1987) faz referência aos temas geradores, afirma que a percepção e a problematização ${ }^{2}$ dos mesmos podem significar a superação de "situações limite", muitas vezes interpretadas como imutáveis e intransponíveis pelos indivíduos.

A equipe envolvida no projeto "Recreio nas Férias", na Vila Jones, era composta por dois coordenadores de núcleo, dois monitores esportivo e dois monitores complementares, sendo que, em cada turno, ficavam responsáveis: um coordenador de núcleo, um monitor esportivo e um monitor complementar. Todas as ações do projeto estavam subordinadas à coordenação

\footnotetext{
${ }^{2} \mathrm{Na}$ perspectiva freiriana, problematizar consiste em detectar a partir da "leitura do mundo" uma determinada realidade, tomando consciência crítica dela, avaliando sua razão de ser e questionando seus aspectos um a um.

3 "[...] são barreiras que o ser humano encontra em sua caminhada, diante das quais pode assumir várias atitudes, como se submeter a elas ou, então, vê-las como obstáculos que devem ser vencidos. Diante dessas barreiras, pode unir a esperança com a prática e agir para que a situação se modifique ou simplesmente se deixar levar pela desesperança" (VASCONCELOS \& BRITO, 2006, p.179).
} 
geral do programa, responsável por um total de 70 núcleos em funcionamento no município.

Tabela 1. Relação de profissionais envolvidos.

\begin{tabular}{|c|c|c|}
\hline Profissionais & Quantidade & Atuação \\
\hline $\begin{array}{l}\text { Coordenador } \\
\text { de núcleo }\end{array}$ & 02 & $\begin{array}{l}\text { Coordenação } \\
\text { centralizada no } \\
\text { núcleo }\end{array}$ \\
\hline $\begin{array}{l}\text { Monitor } \\
\text { esportivo }\end{array}$ & 02 & $\begin{array}{c}\text { Desenvolvimento } \\
\text { de atividades no } \\
\text { núcleo }\end{array}$ \\
\hline $\begin{array}{c}\text { Monitor } \\
\text { complementar }\end{array}$ & 02 & $\begin{array}{c}\text { Auxiliar das } \\
\text { atividades } \\
\text { desenvolvidas no } \\
\text { núcleo }\end{array}$ \\
\hline
\end{tabular}

O processo de implementação do "Recreio nas Férias" foi dividido em cinco etapas: (1) apresentação do projeto e formação de pessoal; (2) diagnóstico; (3) planejamento da programação; (4) execução da programação; (5) avaliação e continuidade.

A primeira etapa consistiu na apresentação do projeto - resultado da ação piloto em alguns municípios brasileiros - e formação das equipes de trabalho de cada núcleo. Esta etapa teve como objetivo apresentar os fundamentos do "Recreio nas Férias" e capacitar para as ações administrativas e práticas a coordenação geral e pedagógica. Após isso, foram capacitados os coordenadores de núcleo, apresentando todos os fundamentos do projeto desde as primeiras ações teóricas, como diagnóstico e planejamento, até os relatórios finais das atividades desenvolvidas no núcleo. Esta etapa teve duração de três dias e a capacitação das equipes foi realizada por uma equipe colaboradora do Ministério do Esporte.

A segunda etapa consistiu na realização de um diagnóstico do entorno do núcleo. Participaram desta etapa: coordenadores setoriais e coordenadores de núcleo. O mapeamento seguiu 0 padrão proposto pela Secretaria Nacional de Esporte Educacional/ME, contemplando as seguintes informações básicas necessárias para desenvolvimento do planejamento:

1. Identificar as características do público alvo, como idade, sexo, nível de escolaridade, entre outros;

2. Quais as atividades que são desenvolvidas de forma sistemática e eventual no núcleo e em seu entorno?
3. Qual a natureza das atividades desenvolvidas no núcleo (físico esportiva, artística, manual, social, turística, intelectual)?

4. Quais são os interesses predominantes no núcleo?

5. Quais os espaços sociais, culturais e esportivos de cada localidade que podem ser utilizados durante a realização do projeto?

6. O que é lazer para o público alvo?

7. O que o público alvo faz durante o tempo de lazer?

8. Quais os principais problemas envolvendo os temas geradores propostos: em janeiro "Meio Ambiente" e em julho "Valores Olímpicos".

Embora o objetivo apontado pelas diretrizes do programa delimitasse 0 atendimento às crianças na faixa etária entre 7 e 17 anos, no núcleo da Vila Jones predominou o atendimento a crianças de 7 a 12 anos do sexo masculino, todos devidamente matriculados em escola regular. Percebeu-se que a população atendida tinha um nível econômico bem diversificado, levando-se em consideração que o núcleo Vila Jones atende uma região com muitos bairros.

A infraestrutura do núcleo para prática de atividades esportivas e de lazer dispunha de: duas quadras poliesportivas, campo de areia, piscina, espaços para desenvolvimento de atividades complementares e pedagógicas, banheiros e bebedouros.

A população utilizava de maneira espontânea a estrutura física do núcleo da Vila Jones para desenvolver atividades esportivas e de lazer. $O$ uso mais frequente do espaço acontecia aos finais de semana e, após as 18 horas dos dias úteis, especialmente pelo público jovem e adulto. As atividades desenvolvidas por esta população eram, especialmente: caminhada, jogos de basquete e futsal.

Próximo ao núcleo existia o Centro de Integração e Valorização do Idoso (CIVI) que oferecia atividades sociais e esportivas para idosos. Poucos eram os espaços do núcleo que podiam ser utilizados para atividades. O CIVI era um deles, pois contava com um amplo salão social que possibilitou o desenvolvimento de diversas atividades culturais e sociais para grandes públicos. 
Embora a praça de esportes da Vila Jones possuísse um amplo espaço verde, a população local ainda carecia de informações acerca da manutenção e do uso dos espaços públicos. Os temas geradores desenvolvidos nas duas edições do "Recreio nas Férias" buscaram identificar esses problemas, incentivando a população a melhor utilizar os espaços e equipamentos de lazer do bairro.

A partir de um diagnóstico que explicitou determinadas problemáticas, buscamos estabelecer os objetivos esperados para o projeto nas referidas temporadas. As diretrizes do projeto "Recreio nas Férias" apontam a necessidade de delimitar objetivos gerais e específicos. Oliveira e Forne (2009) sugerem cuidados necessários para que os objetivos relacionem-se entre si, buscando especificar o conhecimento que o participante pode levar para sua vida; organizar os objetivos de maneira que avance para um estágio posterior, o que Marcellino (1995) denominou de um avanço no nível de participação de conformistas para críticos e criativos. Oliveira e Forne (2009) ainda destacam a necessidade de garantir a clareza dos objetivos para que possam ser compreendidos por todos, servindo como um desafio para o grupo e como fator estimulante à sua superação.

Tal perspectiva também é compartilhada por Silva $(2008$, p.63) a partir do entendimento de que os temas não podem ser "coisas", objetivos que estejam desconectados do contexto da realidade das crianças que participam da programação, arriscando-se assim a se constituírem como programações ingênuas e vazias. Para Freire (1987, p. 98), investigar os temas geradores é investigar "o pensar dos homens referido à realidade, é investigar seu atuar sobre a realidade, que é a sua práxis".

$\mathrm{Na}$ experiência do núcleo da Vila Jones a definição dos objetivos foi realizada pelos coordenadores pedagógicos e de núcleo, considerando o diagnóstico inicial. O quadro abaixo ilustra esta definição:

Quadro 1. Exemplo de objetivos gerais e específicos.

\section{Objetivos gerais:}

- Proporcionar às crianças que participam do "Recreio nas Férias" atividades diferenciadas daquelas vivenciadas no núcleo. Levando-se em consideração os diversos aspectos lúdicos, esportivos, artísticos, sociais e culturais, buscando oferecer a criança prazer e diversão em seu tempo livre.

\section{Objetivos específicos:}

- Proporcionar às crianças uma ampliação em sua vivencia lúdica, esportiva, artística, social e cultural, sem deixar de considerar suas experiências anteriores e sua bagagem motora;

- Estimular um maior conhecimento sobre a natureza e seu entorno, compreendendo sua importância para a sobrevivência humana e consequentemente conscientizar para a preservação e o respeito pela mesma;

- Estimular a reflexão sobre o respeito ao próximo e a comunidade que o cerca, a partir de atividades com materiais reciclados e adaptados;

- Resgatar e promover diferentes vivências culturais, possibilitando uma ampliação na bagagem motora e no conhecimento sobre outras culturas e diferentes tipos de esportes.

Após a definição dos objetivos, inicia-se a terceira etapa: o planejamento da programação e das atividades, um processo árduo e fundamental para a realização do "Recreio nas Férias" a partir da pesquisa e seleção dos conteúdos. Este processo envolve não apenas os coordenadores pedagógicos e os de núcleo, mas toda a equipe do projeto, pois desta forma,

o componente lúdico do lazer teria condições de se manifestar na colônia de férias, não só como produto [...], mas como processo situado e construído coletivamente com os diferentes grupos (SILVA, 2007).

Para tanto, se fez necessário o envolvimento dos interessados de diversos segmentos, entre eles: a própria população, instituições do bairro e, particularmente, 0 grupo de crianças beneficiadas. Ao compreender os sentidos que as atividades assumem para os grupos de crianças, poderíamos criar condições que permitissem o acesso a diferentes níveis de conhecimento e a vivência dos conteúdos culturais do lazer. 
Silva (2007) ainda ressalta que o planejamento das atividades das colônias de férias deve acontecer de forma descentralizada. Ainda, deve ser fundamental que as propostas, sejam 0 resultado de um trabalho em equipe, preferencialmente multidisciplinar, e que o ponto de partida das ações sejam os interesses, as necessidades e as expectativas dos participantes. Para tanto, os conteúdos devem apontar para a inclusão e efetiva participação de todos, equilibrando 0 ato de pensar à prática das atividades, direcionadas fundamentalmente ao tema gerador em questão.
Na experiência do "Recreio nas Férias" na Vila Jones, os conteúdos foram selecionados a partir dos problemas verificados na fase de diagnóstico, buscando apresentar atividades que iniciem o processo de conscientização e solução dos problemas presentes no núcleo.

Os conteúdos selecionados foram organizados em fichas de atividades adaptadas a partir da sugestão dos repertórios de atividades de Marcellino (2006, 2007). Isso permite organizar um material com linguagem acessível para qualquer integrante da equipe e, até mesmo para as crianças, conforme apresentado no quadro a seguir:

Quadro 2. Ficha de atividades adaptada para o planejamento do "Recreio nas Férias".

\begin{tabular}{|c|c|}
\hline Nome da atividade & Mural ecológico \\
\hline Objetivo & $\begin{array}{l}\text { Identificar problemas ambientais e realizar uma oficina de criatividade para } \\
\text { discutir as possíveis soluções. }\end{array}$ \\
\hline Descrição & $\begin{array}{l}\text { Após encontrar os problemas ambientais os participantes deverão propor e } \\
\text { expor as soluções. }\end{array}$ \\
\hline Recursos necessários & Cartolinas, folhas de papel sulfite, lápis, giz de cera, canetas hidrográficas. \\
\hline Montagem & $\begin{array}{l}\text { Cada equipe receberá folhas de papel sulfite e duas cartolinas, uma para os } \\
\text { problemas e outra para as soluções. }\end{array}$ \\
\hline Funcionamento & $\begin{array}{l}\text { Um grupo de crianças de cada uma das equipes, com a ajuda de um } \\
\text { animador, terá a responsabilidade de reconhecer nas ruas ao redor do núcleo } \\
\text { os problemas ambientais e anotá-los em uma folha de papel sulfite. Outro } \\
\text { grupo procurará problemas ambientais no interior do núcleo e anotará da } \\
\text { mesma maneira. Após um determinado tempo todos retornam e discutem } \\
\text { entre si as soluções para esses problemas. Tanto os problemas quanto as } \\
\text { soluções discutidas deverão ser transcritas para uma cartolina. } \\
\text { Proporcionar uma discussão entre os grupos se houveram problemas em } \\
\text { comum, verificar outras possibilidades de solução, entre outros. As soluções } \\
\text { são apresentadas por um representante do grupo, após isso o professor } \\
\text { mediador sugere que os outros grupos façam criticas e apontem diferentes } \\
\text { soluções para este mesmo problema. }\end{array}$ \\
\hline Possibilidade de utilização & Crianças acima de sete anos. \\
\hline $\begin{array}{l}\text { Possibilidade de } \\
\text { adaptação }\end{array}$ & $\begin{array}{l}\text { Podem-se procurar noticias em jornais ao invés de procurar no núcleo. } \\
\text { Dependendo da condição do local, espaço, idade das crianças, etc. }\end{array}$ \\
\hline $\begin{array}{l}\text { Experiências já } \\
\text { desenvolvidas }\end{array}$ & Esta atividade já foi desenvolvida em consultorias de educação ambiental. \\
\hline Outras observações & \\
\hline
\end{tabular}

Outro fator relevante do processo de planejamento da programação do "Recreio nas Férias" se refere a diversidade de conteúdos culturais proporcionando atividades físicoesportiva, artística, manual, social, turística, intelectual. Cabe destacar a importância de considerar o ócio, ou a possibilidade de "nada fazer" na programação, apesar dessa questão ainda ser muito polêmica, uma vez que a visão que prevalece no senso comum é a de que a criança tem que ser o tempo todo tutelada, pois o tempo ocioso é entendido como "pernicioso".

Após a organização da programação das atividades, estas são organizadas numa planilha simples para uma fácil visualização e identificação da atividade que será desenvolvida em determinado momento. Esse material foi disponibilizado para as crianças, pais e 
comunidade, para que pudessem identificar as atividades que mais lhe agradavam.

Planejar as atividades a serem desenvolvidas é de grande importância, no entanto essas ações devem seguir juntamente com 0 bom desenvolvimento dos papéis de cada um dos envolvidos no projeto, fazendo as alterações necessárias conforme o desenvolvimento das ações.

Quadro 3. Exemplo de programação.

\begin{tabular}{|c|c|c|c|c|c|}
\hline \multirow{2}{*}{ Horários } & \multicolumn{5}{|c|}{ Dias da Semana } \\
\hline & Segunda & Terça & Quarta & Quinta & Sexta \\
\hline $\begin{array}{l}\text { 09h00 às } \\
\text { 9h15 }\end{array}$ & Apresentação & Aqua Play & $\begin{array}{c}\text { Jornal } \\
\text { ecológico }\end{array}$ & \multirow{9}{*}{$\begin{array}{c}\text { DIA DO } \\
\text { PASSEIO }\end{array}$} & $\begin{array}{c}\text { Brincadeiras } \\
\text { populares }\end{array}$ \\
\hline $\begin{array}{l}\text { 09h15 às } \\
10 \text { h00 }\end{array}$ & $\begin{array}{c}\text { Separação das } \\
\text { equipes e } \\
\text { confecção dos } \\
\text { emblemas }\end{array}$ & Fut dengue & $\begin{array}{l}\text { Jornal } \\
\text { ecológico }\end{array}$ & & $\begin{array}{l}\text { Brincadeiras } \\
\text { populares }\end{array}$ \\
\hline $\begin{array}{c}10 \mathrm{~h} 00 \text { às } \\
10 \mathrm{~h} 30\end{array}$ & LANCHE & LANCHE & LANCHE & & LANCHE \\
\hline $\begin{array}{c}10 \mathrm{~h} 30 \text { às } \\
12 \mathrm{~h} 00\end{array}$ & $\begin{array}{c}\text { Dinâmicas em } \\
\text { grupo }\end{array}$ & $\begin{array}{c}\text { Gincanas } \\
\text { poliesportivas e } \\
\text { gincanas de texto } \\
\text { sobre o tema } \\
\text { gerador }\end{array}$ & $\begin{array}{l}\text { Gincana } \\
\text { ecológica e } \\
\text { gincana } \\
\text { aquática }\end{array}$ & & $\begin{array}{l}\text { Confecção de } \\
\text { fantoches em } \\
\text { material } \\
\text { reciclado }\end{array}$ \\
\hline $\begin{array}{c}12 \mathrm{~h} 00 \text { às } \\
13 \mathrm{~h} 00\end{array}$ & ALMOÇO & ALMOÇO & ALMOÇO & & ALMOÇO \\
\hline $\begin{array}{c}13 \mathrm{~h} 00 \text { às } \\
14 \mathrm{~h} 00\end{array}$ & $\begin{array}{l}\text { Gincana de } \\
\text { solicitação }\end{array}$ & Mural ecológico & $\begin{array}{c}\text { Splash e jogos } \\
\text { de quadra }\end{array}$ & & $\begin{array}{c}\text { Preparação da } \\
\text { terra }\end{array}$ \\
\hline $\begin{array}{c}14 \mathrm{~h} 00 \text { às } \\
15 \mathrm{~h} 00\end{array}$ & Golfe reciclado & $\begin{array}{l}\text { Beisebol } \\
\text { reciclado }\end{array}$ & Pique dengue & & Plantação de \\
\hline $\begin{array}{c}15 \mathrm{~h} 00 \text { às } \\
15 \mathrm{~h} 30\end{array}$ & LANCHE & LANCHE & LANCHE & & mudas \\
\hline $\begin{array}{c}15 \mathrm{~h} 30 \text { às } \\
16 \mathrm{~h} 30\end{array}$ & \multirow{2}{*}{$\begin{array}{c}\text { Gincana } \\
\text { poliesportiva } \\
\text { (UNDOKAI) }\end{array}$} & \multirow{3}{*}{$\begin{array}{l}\text { Baú de } \\
\text { reciclagens }\end{array}$} & \multirow{3}{*}{$\begin{array}{c}\text { Teatro sobre a } \\
\text { dengue }\end{array}$} & & \multirow{3}{*}{$\begin{array}{c}\text { Festa de } \\
\text { despedida com } \\
\text { música, lanche } \\
\text { e sessão de } \\
\text { fotos }\end{array}$} \\
\hline $\begin{array}{c}16 \mathrm{~h} 30 \text { às } \\
16 \mathrm{~h} 45\end{array}$ & & & & & \\
\hline $\begin{array}{l}16 \mathrm{~h} 45 \text { às } \\
17 \mathrm{h00}\end{array}$ & $\begin{array}{l}\text { Futebol/ } \\
\text { basquete } \\
\text { ecológico }\end{array}$ & & & RETORNO & \\
\hline 17h00 & SAÍDA & SAÍDA & SAÍDA & SAÍDA & SAÍDA \\
\hline
\end{tabular}

Para Oliveira e Forne (2009), os coordenadores do núcleo são os principais responsáveis pelo acontecimento das atividades e devem zelar pelo bem estar de todos durante a execução do "Recreio nas Férias". Além disso, cabe ainda ao coordenador de núcleo: 1. verificar o recebimento dos materiais esportivos e pedagógicos, bem como o lanche para os participantes; 2 . inscrever as crianças participantes no projeto; 3. distribuir as camisetas e os bonés; 4. verificar diariamente a lista de frequência de crianças e monitores; 5 . organizar os horários de acordo com a planilha de atividades e 6 . incentivar um clima de integração, não apenas nas práticas de atividades, mas reunindo a equipe de professores/monitores antes do início de cada período para fazer um balanço de tudo o que aconteceu, buscando soluções para os possíveis problemas.

Tal perspectiva parece reforçar a reflexão inicial apontada pela literatura de predomínio de programas, projetos e ações de caráter assistencial, tecnicista e ocupacional, centralizadas em um profissional com competência técnica específica, quase afirmando certa "incompetência" da comunidade para participar do processo de planejamento e ser coconstrutora da programação. 
Os professores e monitores, segundo as diretrizes do programa, deviam seguir a orientação dos coordenadores auxiliando-os no que fosse necessário, tanto no desenvolvimento das atividades quanto na organização, buscando sempre motivar cada participante e envolvê-los nas atividades realizadas. No entanto, a perspectiva de motivação esteve sempre atrelada aos objetivos propostos pela coordenação, cabendo aos monitores apenas a função de motivador, desconsiderando em sua grande parte seus interesses e pontos de vista a cerca do tema desenvolvido. A relação coordenador/monitor através de uma práxis dialógica, como destacado por Silva (2008), poderia se constituir numa alternativa para aproximar as ações de cada envolvido no projeto visando à solução aos problemas encontrados.

Isso demonstra que o "Recreio nas Férias" não tem se constituído - ao menos considerando suas diretrizes e o observado na realidade do núcleo da Vila Jones - numa política participativa, guardando ranços históricos de outras políticas de esporte e lazer. Em especial, no que diz respeito à estrutura de recursos humanos, o programa valoriza relações hierárquicas de planejamento, separando as questões estratégicas e o planejamento da ação técnica e operacional. Essa ruptura entre "os que planejam" e "os que executam" o planejamento pode ser um fator limitante no desenvolvimento do projeto. Conforme aponta Silva (2008), na maioria das vezes existem divergências em relação aos conceitos centrais da proposta, o que pode esvaziar a dimensão da participação e qualquer possibilidade da experiência do lazer e construção da cidadania em detrimento de uma vivência tutelada, visando ocupar o tempo dos participantes com "atividades saudáveis".

A atuação dos profissionais envolvidos na etapa de execução da programação de atividades (quarta etapa do processo de planejamento) se dava de forma centralizada. Ao coordenador cabia a função de distribuir as atividades, organizandoas para que todas ocorressem conforme 0 planejado. Aos monitores cabia a função de monitorá-las, seguindo a orientação do coordenador que intervinha nos momentos necessários, buscando soluções para os problemas ou imprevistos. Embora todas as atividades desenvolvidas fossem organizadas antecipadamente, era possível realizar alterações de acordo com as circunstâncias ou necessidades do grupo.

No término das atividades, o grupo de profissionais se reunia para a realização de relatórios de avaliação, detectando conflitos e buscando soluções para problemas. Além disso, o grupo acrescentava ou alterava as atividades do dia seguinte, levando em consideração as ações decorridas no dia.

Finalmente, a quinta etapa do processo de planejamento era: a avaliação e a definição do plano de continuidade. $\mathrm{Na}$ literatura especializada verificamos que se o planejamento almeja alcançar objetivos, é necessário que sejam utilizados instrumentos de avaliação que verifiquem se objetivos esperados foram alcançados e se houveram outros resultados não esperados (DUMAZEDIER, s/d). Da mesma forma, é fundamental verificar se as respostas foram positivas ou negativas. "Esses instrumentos buscam readequar constantemente as ações, diagnosticar e solucionar problemas e buscar novos rumos para o desenvolvimento de futuras programações" (SILVA, 2007, p. 74). Para Marcelino (2007), as avaliações só farão sentido se estiverem ligadas às ações diárias do projeto como prática que qualifica a ação, gerando a reflexão sobre a ação, aprimorando a práxis pedagógica dos envolvidos e não como forma de punição ou controle.

Nesse sentido, as principais estratégias de avaliação utilizadas no "Recreio nas Férias" da Vila Jones foram: 1. reuniões de avaliação diárias, organizadas na forma de rodas de conversa no início e no final dos períodos; 2. relatórios diários da equipe envolvida, onde eram descritos a evolução das atividades, os problemas encontrados, entre outros aspectos importantes que viessem ocorrer no período em questão; 3 . avaliação de presença de professores/monitores e dos beneficiados no projeto, a qual era realizada através de uma simples lista de frequência. Todas estas avaliações eram encaminhadas ao coordenador pedagógico do projeto. Além das avaliações realizadas diariamente, ao final do projeto "Recreio nas Férias", existiam os formulários de avaliação de preenchimento obrigatório do Ministério do Esporte, entre eles:

1. Formulário de avaliação, destinados aos beneficiados, preenchidos por dois participantes do núcleo - um na faixa etária de 7 a 11 anos e 
outro na faixa etária de 12 a 17 e enviado ao coordenador geral;

2. Formulário de registro e avaliação sobre a realização do projeto em cada local, a ser preenchido pelos professores e todos os monitores atuantes e enviado ao coordenador geral;

3. Formulário de registro e avaliação por núcleo, a ser preenchido pelo coordenador geral do núcleo e enviado ao coordenador geral;

4. Formulário de registro e avaliação por convênio, a ser preenchido pelo coordenador geral do "Recreio nas Férias" e enviado a SNEED/ME pelo coordenador geral.

Observa-se que os instrumentos de avaliação utilizados durante e ao final do "Recreio nas Férias" eram destinados a níveis de coordenação diferentes. Essa distribuição possibilitou uma avaliação ampla, na qual os diversos agentes envolvidos tiveram a possibilidade de verificar se os objetivos pré-definidos foram, ou não, alcançados.

A análise dos instrumentos de avaliação era de responsabilidade da coordenação pedagógica. Através deles eram delimitados e classificados os principais pontos positivos e negativos do projeto. Esses dados serviam para definir as ações que deveriam permanecer, ou não, nas atividades cotidianas do programa Segundo Tempo. No entanto, esses dados não eram discutidos nos vários níveis da gestão do "Recreio nas Férias" e também não foram sistematizados num plano de continuidade. Isso implicou que após as duas temporadas do "Recreio nas Férias", o núcleo do Segundo Tempo retomou suas atividades normais, sem aproveitar os resultados da temporada.

\section{Considerações finais}

É fato que um processo bem planejado aumenta consideravelmente as chances de obtenção de resultados mais efetivos. Em projetos sociais como o "Recreio nas Férias", atingir os objetivos planejados é considerar as diferentes possibilidades geradas, entre elas 0 desenvolvimento de atividades que insiram os participantes ao meio em que convivem. Os resultados podem resultar na quebra de tabus, ampliação dos convívios sociais, diminuição de preconceitos, abertura de leques de conhecimento e, acima de tudo, vivência do esporte e do lazer e aos aspectos que o cerca (e.g., atividades sociais, turísticas, artísticas, físicas, intelectuais e manuais). Essas atividades, nas ações cotidianas do Programa Segundo Tempo, acabam sendo esquecidas ou omitidas pela prática do esporte por si e para si mesmo.

O diálogo entre teoria e prática vai além da obtenção de bons resultados. $O$ ato de organizar um planejamento e executá-lo nos remete a diferentes aspectos que merecem ser considerados. O planejar no "Recreio nas Férias" deveria destinar-se também aos coordenadores, professores e monitores, podendo se constituir num momento propício de diálogo entre os diferentes níveis de gestão, acarretando maior integração entre os mesmos.

Verifica-se que os processos de planejamento e avaliação, assim como suas respectivas ações práticas, necessitam a cada dia ser aprimoradas de forma a qualificar as políticas públicas setoriais de esporte e lazer, garantindo a ampla participação dos envolvidos em seu processo de implementação e, principalmente no exercício do controle social.

Os registros até então organizados neste relato de experiência se referem às temporadas de janeiro e julho de 2010. O processo de planejamento da terceira edição do "Recreio nas Férias" teve inicio em setembro de 2010. No entanto, um mês depois, as atividades do Segundo Tempo foram interrompidas devido a problemas no processo de gestão administrativo financeira, o que acarretou na descontinuidade do programa e do projeto "Recreio nas Férias" na Vila Jones e nos demais 69 núcleos do município.

Parece que ainda levaremos algum tempo para superar determinadas perspectivas históricas em relação às políticas de esporte e lazer. Enquanto isso, ao refletir e analisar criticamente nossa própria prática temos a oportunidade de compartilhar experiências e contribuir de alguma forma com o processo de democratização do esporte e lazer como direitos sociais, numa mudança que não pode acontecer apenas "de cima para baixo".

\section{Referências}

AMERICANA. Plano Diretor de Desenvolvimento Integrado do Município de Americana. Câmara Municipal de Americana, 2008. 
BONALUME, C. R. et al. Diretrizes norteadoras de um programa de descentralização e democratização do lazer: a experiência de Caxias do Sul. In: Nelson Carvalho Marcellino. (Org.). Lazer e esporte. 1 ed. Campinas: Autores Associados, 2001.

BRAMANTE, A. C. Qualidade no gerenciamento do lazer. In: BRUHNS, Heloísa T. (Org.). Introdução aos estudos do lazer. Campinas, Editora UNICAMP, 1997.

BRASIL. Documento Final. II Conferência Nacional do Esporte. Brasília, Ministério do Esporte, 2006.

BRASIL. Manual de Diretrizes: Recreio nas Férias. Brasília, Secretaria Nacional de Esporte Educacional, 2010.

CARVALHO, M.C.M. de. Metodologia Científica: fundamentos e técnicas. 16ed. Campinas, Papirus, 2005.

DUMAZEDIER, J. Questionamento teórico do lazer. Porto Alegre, CELAR, s.d.

FILGUEIRA, J. C. M. Prefácio. In: OLIVEIRA, A. A. B. O.; PIMENTEL, G. G. A. (Orgs). Recreio nas Férias: reconhecimento do direito ao lazer. Maringá: Eduem, 2009.

FREIRE, P. Pedagogia do oprimido. 17ed. Rio de Janeiro: Paz e Terra, 1987.

FREIRE, P. Ação cultural para a liberdade - e outros escritos. 12ed. São Paulo, Paz e Terra, 2007.

MARCELLINO, N. C. Lazer e educação. 3ed., Campinas, Papirus, 1995.

MARCELLINO, N. C. Políticas setoriais de lazer: o papel das prefeituras. Campinas, Autores Associados, 1996.

MARCELLINO, N. C. Lazer e esporte - políticas públicas. Campinas, Autores Associados, 2001.

MARCELLINO, N. C. Pedagogia da Animação. 7ed. Campinas: Papirus, 2005.

MARCELLINO, N. C. Repertório de atividades de recreação e lazer por fases da vida. Campinas, Papirus, 2006.

MARCELLINO, N. C. Subsídios para uma política de lazer - o papel da administração municipal. In: MARCELLINO, N.C. Políticas Públicas de Lazer. Campinas, Editora Alínea, 2008.
MARCELLINO, N. C.; ZINGONI, P.; PINTO, L. M. S. M.. Como fazer projetos de lazer: elaboração, execução e avaliação. Campinas, SP: Papirus, 2007.

OLIVEIRA, A. A. B. O.; FORNE, L. Planejar: considerações para o Projeto Recreio nas Férias. In: OLIVEIRA, A. A. B. O.; PIMENTEL, G. G. A (Orgs). Recreio nas Férias: reconhecimento do direito ao lazer. Maringá, PR: Eduem, 2009.

PINTO, L. M. S. M. Políticas Públicas de Lazer no Brasil: uma história a contar. In: MARCELLINO, N.C. Políticas Públicas de Lazer. Campinas, Editora Alínea, 2008.

RODRIGUES, R. O papel do Estado nas Políticas Sociais: elementos para discussão sobre a gestão das Políticas Públicas de Lazer no Brasil. In: MARCELLINO, N.C. Políticas Públicas de Lazer. Campinas, Editora Alínea, 2008.

SEVERINO, A.J. Metodologia do trabalho científico. São Paulo, Cortez Editora, 2002.

SILVA, D. A. M. Colônia de Férias Temática: construindo uma metodologia de ação.

Monografia. Biblioteca da FEF/Unicamp, 2003.

SILVA, D. A. M. Propostas de animação para Colônias de Férias. In: MARCELLINO, Nelson C. (Org.). Lazer e Recreação: Repertório de Atividades por Ambiente. Campinas: Papirus, 2007.

SILVA, D. A. M. Colônia de Férias Temática: fundamentando a ação a partir das contribuições de Paulo Freire. Dissertação. Programa de PósGraduação em Educação Física da Faculdade de Ciências da Saúde da Universidade Metodista de Piracicaba, 2008. Disponível em:

$<$ http://www.dominiopublico.gov.br>. Acesso em: $10 / 03 / 2011$.

VASCONCELOS, M. L.M. C. \& BRITO, R. H. P. de. Conceitos de educação em Paulo Freire: glossário. Petrópolis, RJ, Vozes, 2006.

ZINGONI, P. Descentralização e participação em gestões municipais de esporte e lazer. In: ISAYAMA, H. F.; WERNECK, C. L. G. Lazer, recreação e educação física. Belo Horizonte, Autêntica, 2003.

ZINGONI, P. Marco Lógico: uma metodologia de elaboração, gestão e avaliação de projeto social de lazer. In: MARCELLINO, N. C.; ZINGONI, P.; PINTO, L. M. S. M.. Como fazer projetos de lazer: elaboração, execução e avaliação. Campinas, SP: Papirus, 2007. 
Endereço:

Débora Alice Machado da Silva

Rua Prof. Antônio da Silveira Bueno, 58

Jardim Chapadão

Campinas - SP Brasil

13070-159

Telefone: (19) 88099704.

e-mail: debeera@hotmail.com

Recebido em: 14 de novembro de 2011.

Aceito em: 4 de abril de 2012.

(c) (P)

Motriz. Revista de Educação Física. UNESP, Rio Claro,

SP, Brasil - elSSN: 1980-6574 - está licenciada sob

Creative Commons - Atribuição 3.0 